\title{
PEMANFAATAN LANGSUNG TEKNOLOGI INFORMASI DALAM DAKWAH ISLAM
}

\author{
Fachrul Kurniawan \\ Fakultas Sains dan Teknologi UIN Maulana Malik Ibrahim Malang \\ Jalan Gajayana No. 50 Malang. Telp. 08885546013 \\ email: fachrulkurniawan873@gmail.com
}

\begin{abstract}
Information technology is evolving so fast these days, like all science also changes following the pace of information technology development, and this is simply due to the development of information technology continue to be done by making use of all existing science. In the world of Islam is often made use of information technology and one of them is used to preach. Today the world of preaching often use information technology to facilitate direct communication between the congregation and resource persons. Not to mention the use of interactive multimedia to further his message. This mission can we find a model like ESQ (Emotional Spiritual Quotient), which is the dominant technology. Data on the use of information technology as a medium of propagation is also seen seen from pegguna Islamic features that can be accessed via the internet, the statistics (Effective Measure) internet users in Indonesia reached 39.1 million (8 world ranking) if taken alone the percentage of 50\% to access Islamic features of the 20 million people who use information technology as a medium of preaching both corporately and individually. And utilization of information technology in the world of preaching will increase when there are moments like the Ramadan month.
\end{abstract}

Teknologi informasi dewasa ini berkembang begitu cepat, seakan semua ilmu pengetahuan juga ikut berkembang mengikuti kecepatan perkembangan teknologi informasi, dan ini wajar karena pengembangan untuk teknologi informasi terus menerus dilakukan dengan memanfaatkan semua ilmu pengetahuan yang ada. Dalam dunia Islam pemanfaatan teknologi informasi seringkali dilakukan dan salah satunya adalah digunakan untuk berdakwah. Dewasa ini dunia dakwah seringkali menggunakan teknologi informasi untuk mempermudah komunikasi langsung antara jamaah dan nara sumber. Belum lagi yang memanfaatkan multimedia agar dakwahnya lebih interaktif. Hal ini bisa dijumpai model 
dakwah seperti ESQ (Emotional Spiritual Quotient), dimana teknologi sangatlah dominan. Data penggunaan teknologi informasi sebagai media dakwah juga terlihat terlihat dari pegguna fitur-fitur Islami yang bisa diakses lewat internet, data statistik (Effective Measure) pengguna internet di Indonesia mencapai 39.100.000 (peringkat 8 dunia) jika diambil prosentase 50\% saja yang meng akses fitur Islami maka 20 juta orang yang memanfaatkan teknologi informasi sebagai media dakwah baik secara kelompok maupun secara individual. Dan pemanfaatan teknologi informasi dalam dunia dakwah akan meningkat ketika ada momen seperti bulan Ramadhan.

Key words: information technology, Islam, preaching.

\section{Pendahuluan}

Dalam kurun waktu 10 tahun penduduk dunia bertambah dengan cepatnya, hal ini juga berlaku bagi negera-negara yang penduduknya mayoritas muslim. Kalau dibandingkan perkembangan penduduk yang mayoritas muslim pada pertengahan tahun 1970 an yang hanya berjumlah total sekitar 500 juta orang, dengan jumlah penduduk muslim diseluruh dunia saat ini yang mencapai 1,5 milyar artinya setiap dari empat orang di dunia ini maka satunya adalah orang yang memeluk agama Islam atau seorang muslim. Peningkatan jumlah pemeluk Islam ini bukan semata-mata merupakan pertambahan penduduk di negara-negara yang mayoritas muslim itu bertambah tetapi juga dikarenakan faktor mualaf yang semakin bertambah banyak. Artinya faktor dakwah merupakan sarana produktif untuk mengajak semua orang di dunia ini untuk mengenal lebih jauh dengan Islam. Walaupun faktor 11 September 2002 adalah merupakan pemicu bertambahnya mualaf yang masuk ke agama Islam, dan hal ini juga banyak dikarenakan teknologi informasi yang begitu mudah di akses dan dinikmati, hingga semakin mudah mempelajari Islam secara keseluruhan. Masuk Islam dengan terlebih dahulu mempelajarinya adalah faktor terbanyak penambah jumlah pemeluk muslim dunia, dan apalagi didukung oleh teknologi yang berkembang cepat. Ilmu pengetahuan adalah merupakan sarana yang paling rasional untuk mempelajari Islam dengan benar, dan hal ini telah di firmankan oleh Allah SWT:

"Apakah kamu hai orang musyrik yang lebih beruntung) ataukah orang yang beribadat di waktu-waktu malam dengan sujud dan berdiri, sedang ia takut kepada (azab) akhirat dan mengharapkan rahmat Tuhannya? Katakanlah: 'Adakah sama orang-orang yang berilmu dengan orang yang tidak berilmu?' Sesungguhnya hanya orang-orang yang berakallah yang dapat menerima pelajaran" (QS az zumar: 9). 
Dalam sebuah Hadits Rasulullah juga menerangkan tentang keutamaan menggunakan atau menguasai ilmu pengetahuan atau teknologi yaitu Rasulullah SAW juga memerintahkan para orang tua agar mendidik anak-anaknya dengan sebaik mungkin. Sebagaimana disebutkan di dalam Hadits:

"Menuntut ilmu itu diwajibkan bagi setiap muslimin, sesungguhnya Allah mencintai para penuntut ilmu (HR Ahmad)".

Luar biasa karena jaman dahulu pun mendidik dan perlunya menguasai sesuatu keahlian yang beda jaman sudah menjadi perhatian oleh para sahabat maupun Rasulullah sendiri.

Dakwah adalah merupakan kewajiban setiap muslim karena ini merupakan tugas pokok bagi seorang yang telah mengaku berikrar kepada Allah dan Rasul-Nya sebagaimana di firmankan Allah SWT:

"Dan (ingatlah), ketika Kami mengambil janji dari Bani Israil (yaitu): Janganlah kamu menyembah selain Allah, dan berbuat kebaikanlah kepada ibu bapa, kaum kerabat, anak-anak yatim, dan orang-orang miskin, serta ucapkanlah kata-kata yang baik kepada manusia, dirikanlah shalat dan tunaikanlah zakat. Kemudian kamu tidak memenuhi janji itu, kecuali sebahagian kecil daripada kamu, dan kamu selalu berpaling" (QS al Baqarah: 83).

Peristiwa 11 September 2002 dimana semuanya terhenyak dengan diledakkannya kantor pusat perdagangan saham terbesar di dunia yaitu gedung World Trade Centre (WTC) di Amerika Serikat, dengan Islam sebagai tertuduh utama maka mau tidak mau orang muslim di dunia dianggap sebagai ekstrimis semuanya, tetapi Allah SWT dengan kekuasaannya merubah itu semuanya sebagai bagian bahwa Dialah pelindung utama agama Islam. Dengan adanya teknologi informasi yang begitu canggih dan bisa dinikmati oleh semua orang seantero dunia, yang begitu gencar memberitakan Islam sebagai hot news, maka secara tidak langsung itu membantu dakwah Islam untuk tersampaikan ke semua orang di dunia. Walaupun sebenarnya kebenaran pengebom WTC sampai kini belum diketahui secara transparan oleh publik dunia. Stigma yang negatif bisa dirubah menjadi positif dengan memanfaatkan teknologi informasi, dan sebaliknya juga stigma positif bisa menjadi negatif jika sudah masuk dan diolah oleh teknologi informasi, seperti proses yang terjadi dalam teknologi informasi. Jadi tergantung siapa penguasa teknologi informasi dunia karena stigma apapun akan bisa di ubah, teknologi informasi bukan saja hanya sebagai teknologi semata tetapi lebih daripada itu adalah sebagai 
media penyebar informasi yang sangat efektif.

\section{Pembahasan}

\section{Agama versus Saintek (Science dan Technology)}

Di Eropa, sejak abad pertengahan, timbul konflik antara ilmu pengetahuan (sains) dan agama (gereja). Dalam konflik ini sains keluar sebagai pemenang, dan sejak itu sains melepaskan diri dari kontrol dan pengaruh agama, serta membangun wilayahnya sendiri secara otonom. Dalam perkembangannya lebih lanjut, setelah terjadi revolusi industri di Barat, terutama sepanjang abad XVIII dan XIX, sains bahkan menjadi "agama baru" atau "agama palsu"(Pseudo Religion). Dalam kajian teologi modern di Barat, timbul mazhab baru yang dinamakan "saintisme" dalam arti bahwa sains telah menjadi isme, ideologi bahkan agama baru.

Namun sejak pertengahan abad XX, terutama setelah terjadi penyalahgunaan iptek dalam perang dunia I dan perang dunia II, banyak pihak mulai menyerukan perlunya integrasi ilmu dan agama, iptek dan imtak. Pembicaraan tentang iptek mulai dikaitkan dengan moral dan agama hingga sekarang sehubungan dengan semakin merajalelanya teknologi yang hanya berdasar hanya pada materi sehingga manusia pun dijadikan sebuah percobaan (kasus kloning). Dalam kaitan ini, keterkaitan iptek dengan moral (agama) di harapkan bukan hanya pada aspek penggunaannya saja (aksiologi), tapi juga pada pilihan objek (ontologi) dan metodologi (epistemologinya) sekaligus. Di Indonesia, gagasan tentang perlunya integrasi pendidikan imtak dan teknologi ini sudah lama digulirkan. Profesor B.J. Habibie adalah orang pertama yang menggagas integrasi imtak dan iptek ini. Hal ini, selain karena adanya problem dikotomi antara apa yang dinamakan ilmu-ilmu umum (saintek) dan ilmu-ilmu agama (Islam), juga disebabkan oleh adanya kenyataan bahwa pengembangan iptek dalam sistem pendidikan tampaknya berjalan sendiri, tanpa dukungan asas iman dan takwa yang kuat, sehingga pengembangan dan kemajuan iptek tidak memiliki nilai tambah dan tidak memberikan manfaat yang cukup berarti bagi kemajuan dan kemaslahatan umat dan bangsa dalam arti yang seluas-luasnya.

Kekhawatiran ini, cukup beralasan, karena sejauh ini sistem pendidikan tidak cukup mampu menghasilkan manusia Indonesia yang beriman dan bertakwa kepada Allah SWT sebagaimana diharapkan. Berbagai tindak kejahatan sering terjadi dan banyak dilakukan justru oleh orang-orang yang secara akademik sangat terpelajar, bahkan mumpuni. Ini berarti, aspek pendidikan turut menyumbang dan memberikan saham bagi kebangkrutan 
bangsa yang dirasakan sekarang. Kenyataan ini menjadi salah satu catatan mengenai raport merah pendidikan nasional. Begitu juga pendidikan yang hanya mementingkan aspek agama saja akan menjadikan dunia tidak pada tempatnya atau penyalahgunaan wewenang akan semakin banyak dikarenakan kekurangpahaman tentang ilmu terapan atau teknologi. Karena etika moral akan efektif jika diterapkan pada aplikasi keilmuan terapan karena ilmu tersebut akan diterapkan secara praktis dalam dunia kerja sehingga integrasi adalah hal yang mungkin untuk dilakukan.

\section{Perlunya Penguasaan Teknologi Informasi}

Sudah menjadi pengetahuan umum (common sense) bahwa dasar dari peradaban modern adalah teknologi. Teknologi merupakan dasar dan pondasi yang menjadi penyangga bangunan peradaban modern barat sekarang ini. Masa depan suatu bangsa akan banyak ditentukan oleh tingkat penguasaan bangsa itu terhadap teknologi. Suatu masyarakat atau bangsa tidak akan memiliki keunggulan dan kemampuan daya saing yang tinggi, bila ia tidak mengambil dan mengembangkan teknologi. Bisa dimengerti bila setiap bangsa di muka bumi sekarang ini, berlomba-lomba serta bersaing secara ketat dalam penguasaan dan pengembangan teknologi. Karena dunia secara teknologi informasi berbentuk datar, sehingga sisi dunia akan tampak semua oleh penghuninya. Penguasaan teknologi informasi wajib dilakukan oleh umat Islam karena beberapa hal:

1. Pengembangan teknologi dan ilmu pengetahuan berasal dari sumbersumber negara Islam yang telah dibawa oleh negara-negara barat. Hal ini tentunya juga merupakan perintah Allah SWT: "Hai orangorang beriman apabila dikatakan kepadamu: "Berlapang-lapanglah dalam majlis", maka lapangkanlah niscaya Allah akan memberi kelapangan untukmu. Dan apabila dikatakan: "Berdirilah kamu”, maka berdirilah, niscaya Allah akan meninggikan orang-orang yang beriman di antaramu dan orang-orang yang diberi ilmu pengetahuan beberapa derajat. Dan Allah Maha Mengetahui apa yang kamu kerjakan (QS al Mujaadilah: 11).

2. Allah akan memberikan kearifan dan juga ketentraman kepada siapa saja yang menguasai ilmu pengetahuan dan teknologi. Agar umat muslim tidak bergantung kepada dunia barat (umat lain), dan bisa membuat solusi-solusi terhadap persoalan umat. Salah satu contoh adalah ketika umat Islam bisa merencanakan pemetaan zakat untuk 
mengentaskan kemiskinan dengan memanfaat sistem informasi geografis (GIS). Umat Islam menguasai teknologi maka akan ada rasa damai dikalangan semua umat di dunia. Berikut ini disebutkan dalam al Quran: "Allah berikan al Hikmah (Ilmu pengetahuan, hukum, filsafat dan kearifan) kepada siapa saja yang Dia kehendaki. Dan barangsiapa yang dianugrahi al Hikmah itu, benar-benar ia telah dianugrahi karunia yang banyak. Dan hanya orang-orang berakallah yang dapat mengambil pelajaran (berdzikir) dari firman-firman Allah" (QS al Baqarah: 269).

3. Penguasaan teknologi Informasi akan membuat umat Islam untuk selalu mengetahui informasi terkini dan tidak gampang untuk dipecah belah oleh umat lain, sehingga dengan menguasai teknologi informasi akan mendekatkan persatuan dan kesatuan umat. Peringatan Nabi Muhammad lewat Hadits yang beliau ucapkan 14 abad yang lalu mengenai setiap zaman adalah berbeda, artinya antara zaman sekarang dengan zaman yang akan datang akan berbeda karena perubahan semakin cepat. Rasulullah SAW pun memerintahkan kepada kaum muslimin seluruhnya untuk senantiasa menuntut ilmu dan menguasai ilmu itu sendiri, dalam Hadits disebutkan: "Jadilah engkau orang yang berilmu (pandai) atau orang yang belajar, atau orang yang mau mendengarkan ilmu, atau orang yang menyukai ilmu. Dan janganlah engkau menjadi orang yang kelima maka kamu akan celaka" (HR. Baihaqi).

Dalam sebuah Hadits yang lain Rasulullah SAW bersabda:

"Barang siapa yang menempuh suatu jalan dalam rangka mencari ilmu maka Allah akan memudahkan baginya jalan menuju surga, dan sesungguhnya para malaikat membentangkan sayapnya karena ridla (rela) terhadap orang yang mencari ilmu. Dan sesungguhnya orang yang mencari ilmu akan memintakan bagi mereka siapa-siapa yang ada di langit dan di bumi bahkan ikan-ikan yang ada di air. Dan sesungguhnya keutamaan orang yang berilmu atas orang yang ahli ibadah seperti keutamaan (cahaya) bulan purnama atas seluruh cahaya bintang. Sesungguhnya para ulama itu adalah pewaris para Nabi, sesugguhnya para Nabi tidak mewariskan dinar dan dirham, akan tetapi mereka mewariskan ilmu, maka barang siapa yang mengambil bagian untuk mencari ilmu, maka dia sudah mengambil bagian yang besar" (HR Ahmad, Tirmidzi, Abu Dawud, dan Ibnuu Majjah). 


\section{Integrasi Teknologi dan Dakwah Islam}

Penguasaan teknologi bagi kaum muslim telah dijelaskan sebagaimana disebutkan di dalam Hadits:

"Barangsiapa ingin berjaya di dunia, maka wajib baginya menguasai ilmu; barangsiapa ingin berjaya di kehidupan akhirat maka wajib baginya menguasai ilmu; barangsiapa ingin berjaya di dunia dan akhirat, maka wajib baginya menguasai ilmu" (HR. al Bukhari).

Perubahan lingkungan yang serba cepat dewasa ini sebagai dampak globalisasi dan perkembangan ilmu pengetahuan dan teknologi, harus diakui telah memberikan kemudahan terhadap berbagai aktifitas dakwah Islam. Di sisi lain, memunculkan kekhawatiran terhadap perkembangan perilaku khususnya para pelajar dan generasi muda, dengan tumbuhnya budaya kehidupan baru yang cenderung menjauh dari nilai-nilai spiritualitas. Dakwah Islam memang harus sudah selayaknya untuk dibuat semenarik mungkin (interaktif) dengan memanfaatkan teknologi sebagai alat yang utama. Dari sisi positif, perkembangan teknologi telah memunculkan kesadaran yang kuat pada sebagian pelajar akan pentingnya memiliki keahlian dan keterampilan. Utamanya untuk menyongsong kehidupan masa depan yang lebih baik, dalam rangka mengisi era milenium ketiga yang disebut sebagai era informasi dan era bio teknologi. Ini sekurang-kurangnya telah memunculkan sikap optimis, generasi pelajar umumya telah memiliki kesiapan dalam menghadapi perubahan itu.

Don Tapscott dalam bukunya Grown Up Digital telah melakukan survei terhadap para remaja di berbagai negara. Ia menyimpulkan, ada sepuluh ciri dari generasi nol (zero), yang akan mengisi masa tersebut. Ciri-ciri itu, para remaja umumnya memiliki pengetahuan memadai dan akses yang tak terbatas. Bergaul sangat intensif lewat internet, cenderung inklusif, bebas berekspresi, hidup didasarkan pada perkembangan teknologi, sehingga inovatif, bersikap lebih dewasa, investigative arahnya pada how use something as good as possible bukan how does it work. Mereka pemikir cepat (fast thinker), peka dan kritis terutama pada informasi palsu, serta cek ricek menjadi keharusan bagi mereka (Tapscott, 2009: 81).

Sikap optimis terhadap keadaan sebagian generasi muda ini tentu harus diimbangi dengan memberikan pemahaman, arti penting mengembangkan aspek spiritual keagamaan dan aspek pengendalian emosional, sehingga tercapai keselarasan pemenuhan kebutuhan otak dan hati. Penanaman kesadaran pentingnya nilai-nilai agama memberi jaminan kepada para remaja akan kebahagiaan dan keselamatan hidup, bukan saja selama di dunia tapi 
juga kelak di akhirat.

Ada banyak hal yang sudah dihasilkan oleh teknologi untuk dakwah Islam sebagai bagian dari integrasi itu sendiri, al Quran digital, akses Hadits shahih yang bisa dilakukan dimana saja,silahturahmi yang tidak pernah putus karena sudah ada handphone, jejaring sosial dan sebagainya. Bahkan media pembelajaran yang menyenangkan dengan menggunakan game untuk memperdalam ilmu Islam itu sendiri.

Contoh dari Teknologi Informasi yang dimanfaatkan untuk dakwah Islam:

1. Mushaf Quran

Cetakan

Madinah

* Versi PDF (31 MB)

it

Versi

Microsoft

Word (2.7

MB)

2. Gadget/Widget (24 MB)

it Al-Qur'an

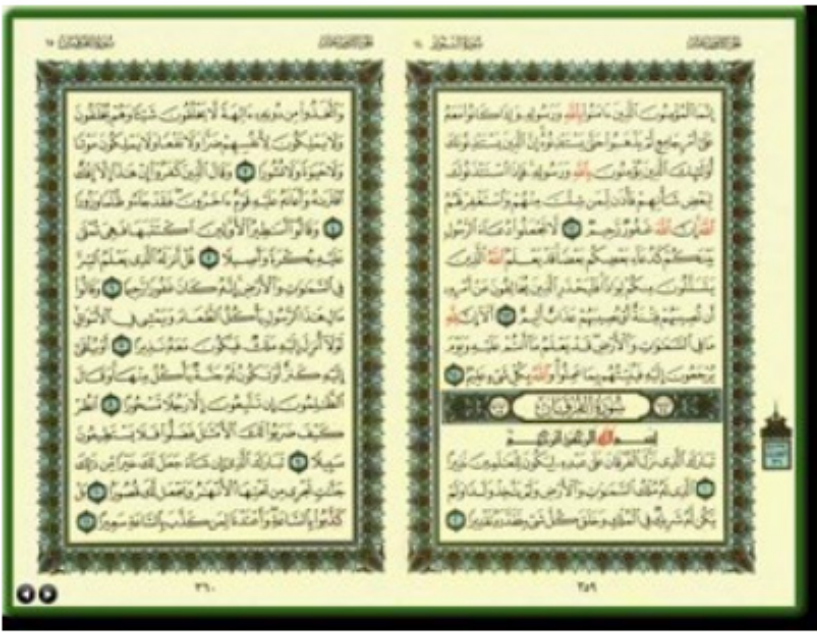

sebagai

Vista Sidebar Gadget

* Al-Qur'an sebagai Yahoo widget

* Al-Qur'an sebagai Macos X Dashboard widget

3. Pocket Qur'an untuk ponsel/PDA/SmartPhone (268 - 820 kB)

Gambar 1. al Quran digital (sumber: myquran.com) 


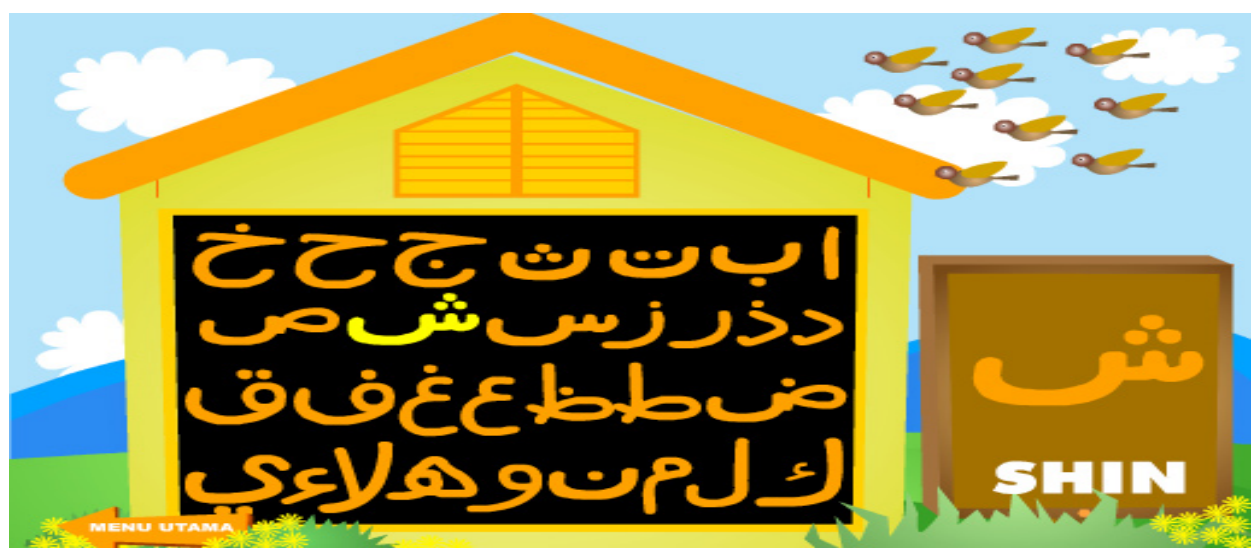

Gambar 2: Game baca huruf hijaiyah (sumber: software game hijaiyah)

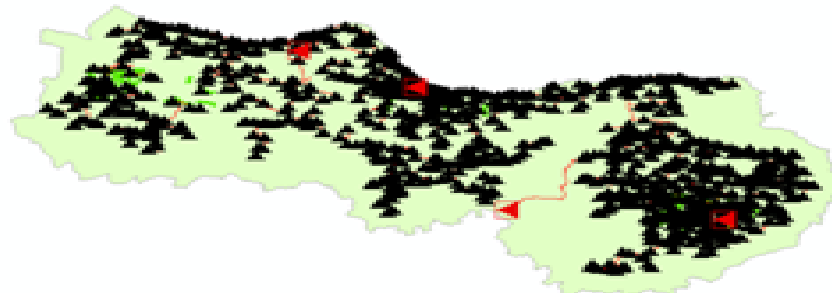

Gambar 3: Aplikasi GIS masjid (sumber: sofware aplikasi GIS)

\section{Islamisasi Ilmu Pengetahuan dan Teknologi}

Ilmu pengetahuan dan teknologi adalah sarana pemecahan masalah mendasar setiap peradaban. Ia adalah ungkapan fisik dari world view di mana dia dilahirkan. Maka bisa memahami mengapa di Jepang yang kabarnya sangat menghargai nilai waktu demikian pesat berkembang budaya "pachinko" dan game. Tentu disebabkan mereka tak beriman akan kehidupan setelah mati, dan tak mempunyai batasan tentang hiburan. Kini umat Islam hanya sebagai konsumen sains yang ada sekarang. Kalaupun mereka ikut berperan di dalamnya, maka secara umum mereka tetap di bawah kendali pencetus sains tersebut. Ilmuwanilmuwan muslim masih sulit menghasilkan teknologi-teknologi eksak apalagi non eksak untuk menopang kepentingan khusus umat Islam. Dunia Islam mulai bangkit (kembali) memikirkan kedudukan sains dalam Islam pada dekade 70-an. Pada 1976 dilangsungkan seminar internasional pendidikan Islam di Jedah dan semakin ramai diseminarkan di tahun 80-an. 
Secara umum, dikenal 4 kategori pendekatan sains Islam (Sardar, 1987: 3):

\section{I'jazul Quran (Mukjizat Al Quran)}

I'jazul Quran dipelopori Maurice Bucaille yang sempat "boom" dengan bukunya "La Bible, le Coran et la Science" (edisi Indonesia: "Bibel, al Quran dan Sains Modern"). Pendekatannya adalah mencari kesesuaian penemuan ilmiah dengan ayat al Quran. Hal ini kemudian banyak dikritik, lantaran penemuan ilmiah tidak dapat dijamin tidak akan mengalami perubahan di masa depan. Menganggap al Quran sesuai dengan sesuatu yang masih bisa berubah berarti menganggap al Quran juga bisa berubah.

\section{Islamization Disciplines}

Islamization Disciplines yakni membandingkan sains modern dan khazanah Islam, untuk kemudian melahirkan text book orisinil dari ilmuwan muslim. Penggagas utamanya Ismail Raji al Faruqi, dalam bukunya yang terkenal, Islamization of Knowledge, 1982. Ide al Faruqi ini mendapat dukungan yang besar sekali dan dialah yang mendorong pendirian International Institute of Islamic Thought (IIIT) di Washington (1981), yang merupakan lembaga yang aktif menggulirkan program seputar islamisasi pengetahuan.

Rencana Islamisasi pengetahuan al Faruqi bertujuan:

1. Penguasaan disiplin ilmu modern.

2. Penguasaan warisan Islam.

3. Penentuan relevansi khusus Islam bagi setiap bidang pengetahuan modern.

4. Pencarian cara-cara untuk menciptakan perpaduan kreatif antara warisan Islam dan pengetahuan modern (melalui survei masalah umat Islam dan umat manusia seluruhnya).

5. Pengarahan pemikiran Islam ke jalan yang menuntunnya menuju pemenuhan pola Ilahiyah dari Allah.

6. Realisasi praktis islamisasi pengetahuan melalui: penulisan kembali disiplin ilmu modern ke dalam kerangka Islam dan menyebarkan pengetahuan Islam.

\section{Membangun Teknologi Informasi Islami}

Ide ini ditujukan untuk membentengi atau menghadapi kompetitor teknologi informasi yang tidak Islami, misalkan bagaimana harus memblokir teknologi informasi yang berbau pornografi atau bagaimana membangun teknologi informasi anti korupsi yang bisa diterapkan dalam pemerintahan. Hal yang paling penting adalah membangun sumber daya manusia ahli TI yang paham akan kebutuhan teknologi informasi yang Islami. 


\section{Menggali Epistimologi Sains Islam (Murni).}

Epistimologi sains Islam murni digali dari pandangan dunia dunia Islam, dan dari sinilah dibangun teknologi dan peradaban Islam. Dipelopori oleh Ziauddin Sardar, dalam bukunya: "Islamic Futures: "The Shape of Ideas to Come” "'(1985). Sardar mengkritik ide al Faruqi dalam bukunya, yang dapat di simpulkan menjadi dua hal penting (Sardar, 1987: 51):

1. Karena sains dan teknologilah yang menjaga struktur sosial, ekonomi dan politik yang menguasai dunia.

2. Tidak ada kegiatan manusia yang dibagi-bagi dalam kotak-kotak: psikologi, sosiologi, dan ilmu politik.

Islamisasi teknologi tidak akan pernah berhasil jika tidak ada keselarasan antara keduanya artinya teknologi tidak bisa dipaksa untuk terus menuruti aturan-aturan dalam Islam. Karena teknologi juga butuh ekspansi untuk bisa berkembang dengan melalui pengujian-pengujian dalam seluruh aspek tidak dalam satu arah kebijakan. Keselarasan ini juga harus didukung oleh kaum agamis untuk bisa belajar tentang teknologi artinya "melek teknologi", tidak harus masuk secara dalam mempelajari teknologi tetapi mengerti sedikit dan tahu karakter teknologi akan sangat membantu dalam islamisasi teknologi. Saya kira hal ini tidak terlalu berlebihan karena inilah dakwah sesungguhnya, dakwah yang selalu dua arah dan tidak satu arah. Pemaksaan hanya akan menimbulkan kesenjangan dan pertanyaan yang tidak bisa memberikan kontribusi kepada integrasi teknologi dan Islam.

\section{Simpulan}

Kejayaan Islam pada masa Dinasti Abbasiyah mencerminkan bahwa Islam adalah agama yang luar biasa. Bahkan Eropa pun seolah-olah tidak berdaya menghadapi kemajuan Islam terutama di bidang teknologinya pada waktu itu. Sekarang kemajuan teknologi dikuasai oleh barat, dan sebagai mayoritas penduduk muslim terbesar dunia hanya sebagai penikmat atau sebagai konsumen dari teknologi yang mereka kembangkan.

Suatu hal yang mungkin jika masyarakat berkolaborasi menciptakan keselarasan untuk memanfaatkan teknologi informasi untuk menjadi senjata dalam dakwah Islamiyah. Tidak perlu berlama-lama dalam menciptakan integrasi teknologi dalam dakwah Islam karena sebenarnya sifat dari teknologi informasi itu adalah menyesuaikan keinginan dari konsumen 
yang akan menikmatinya. Islamisasi teknologi informasi adalah merupakan hal yang seharusnya dapat dinikmati tanpa harus menimbulkan konflik diantara sesama muslim. Karena sebenarnya teknologi itu sudah ada di dalam Islam itu sendiri.

\section{Daftar Pustaka}

Hatta, Ahmad. 2009. Al Quran dan Terjemahan Perkata. Jakarta: Maghfirah Pustaka.

Tapscott, Don. 2009. Grown Up Digital: How the Net Generation is Changing Your World. McGraw Hill.

Sardar, Ziauddin. 1987. Masa Depan Islam. Bandung: Pustaka. 